\title{
¿TIENEN LOS CONTRATOS EFECTOS REALES EN NUESTRO SISTEMA? A PROPÓSITO DE LA DUALIDAD DEL TÍTULO-MODO DE ADQUIRIR
}

\section{Cristián Eduardo AEdo Barrena*}

RESUMEN: El artículo examina la doctrina tradicional, proveniente del derecho romano, de la dualidad del título y los modos de adquirir como presupuesto para la adquisición de derechos reales, en contraposición a la teoría francesa, que consagró en el Code el efecto real de los contratos. Se plantea que, como en otros sistemas, el nuestro presenta casos que se acercan a la regulación del sistema francés, deteniéndonos en el estudio de dos casos precisos: las formas de tradición ficta del artículo $684 N^{o} 5$ del Código Civil y la inscripción constitutiva del contrato de bipoteca.

Palabras Clave: Contrato - título - modo de adquirir - tradición hipoteca.

\section{DO CONTRACTS HAVE REAL EFFECTS IN OUR SYSTEM? ABOUT THE DUALITY OF THE TITLE-WAY OF ACQUIRING}

ABSTRACT: The article examines the traditional doctrine, that comes from the Roman Law, of the duality of the title and the way of acquiring as an assumption for the acquisition of real rights, opposite to the French theory, that confirmed the real effect of contracts in the Code. The author states that our system, as others, presents cases that are closer to the regulation of the French system, carefully studying two specific cases: The forms of fictitious tradition of the article $684 N^{o} 5$ of the Civil Code and the constitutive inscription of the mortgage agreement.

KEY WORDS: Agreement - title - way of acquiring - tradition mortgage.

SUMARIO: I. Introducción. II. Las formas de tradición del numeral 5 del artículo 684 del Código Civil. III. La constitución del derecho real de hipoteca

Abogado. Profesor de Derecho Civil, Universidad Católica del Norte (CHILE). Correo electrónico: caedo@ucn.cl.

Fecha de recepción: 26 de noviembre de 2006.

Fecha de aprobación: 6 de diciembre de 2006. 
¿Efecto real del contrato de bipoteca? 1. Concepto y características que se atribuyen a la bipoteca como derecho real. 2. La bipoteca como contrato. Su carácter solemne y papel de la inscripción. 3. Nuestra bipótesis: la inscripción constitutiva no importa tradición. IV. Conclusiones

\section{INTRODUCCIÓN}

Las fuentes de las obligaciones son los hechos o actos jurídicos de los cuales estas surgen, es decir, se trata de establecer el origen del cual emana la relación jurídica de obligación. Las fuentes de las obligaciones son, en consecuencia, los hechos jurídicos que dan nacimiento al especial vínculo jurídico que denominamos obligación. En este sentido, para muchos autores, las fuentes de las obligaciones equivalen a lo que en la teoría de la causa conocemos como "causa eficiente", esto es, su antecedente generador ${ }^{1}$. En cuanto a esta concepción de causa, ella no responde al elemento de la obligación, sino que atiende a su significación lógica, por tanto la fuente de la obligación es su causa suficiente, toda vez que constituye su razón jurídica, el antecedente del derecho del cual emanan las obligaciones ${ }^{2}$.

Ahora bien, las obligaciones surgen entonces solo de aquellas fuentes que se encuentran precisamente preestablecidas por la ley, de tal suerte que esta última solo admite las fuentes creadas por ella, pues las obligaciones implican una limitación a la libertad económica de los individuos. La doctrina ha elaborado las siguientes definiciones: "Fuente de la obligación es el hecho jurídico que le da nacimiento, que origina o genera la obligación"3. "Se entiende por fuente de las obligaciones los hechos o actos de donde las obligaciones surgen" 4 . Las fuentes de las obligaciones han sido clasificadas tradicionalmente en cinco figuras: el contrato; el cuasicontrato; el delito; el cuasidelito; y la ley (que se agregó posteriormente por los comentaristas del Derecho Romano) $)^{5}$. Al respecto, el profesor Von Tuhr indica: "En la sistemática del Derecho civil es fundamental la clasificación romana de la obligación en dos grupos principales: obligaciones ex contractu y obligaciones ex

Peñailillo Arévalo, Daniel: Obligaciones, Editorial Jurídica de Chile, Santiago, 2003, p. 95 Abeliuk Manasevic, René: Las obligaciones, Editorial Jurídica de Chile, Santiago, 2001, p. 45

ABELIUK: (n. 2), p. 45

Peñailillo: (n. 1), p. 129

En esta materia, hemos seguido muy de cerca la doctrina francesa. Al respecto, FABRÉMagnan, Muriel: Les obligations, Presses Universitaires de France, Paris, 2004, p. 6, señala: "Selon la présentation la plus classique, une personne ne peut etre obligeé evers une autre que lorsque l'une ou l'autrede ces cinq sources est présente: la loi, un contrat, un quasi-contrat, un délit ou en fin un quasi-délit". 
delicto. Esta división hubo de ser completada más tarde por otras dos categorías accesorias: obligaciones quasi ex contractu, semejantes por su contenido a las obligaciones contractuales, aunque entre sus hechos constitutivos faltase el elemento esencial del contrato: el acuerdo de voluntades, y obligaciones quasi ex delicto, o sea los deberes de indemnización que no tenían por fundamento el requisito esencial del delito, la culpa"6.

El origen de esta clasificación arranca de los glosadores medievales, los cuales la tomaron del derecho romano. En este punto existe una discusión, al parecer ya resuelta en la doctrina, en torno a señalar que en el derecho Romano, y según versa un texto de Gayo del Digesto, las obligaciones nacen del contrato, del delito y de otras varias causas (variae causarum figurae). Luego en las instituciones de Justiniano se habría especificado la última expresión y habrían quedado configuradas las cuatro fuentes que permanecieron por muchos siglos antes que se le agregara la ley. El profesor D'ors explica: "Resulta así la siguiente clasificación de las fuentes de las obligaciones civiles y pretorias: delitos, préstamos, estipulaciones y contratos; esta clasificación no aparece enunciada en las obras escolásticas antiguas y modernas, pero corresponde a la realidad del sistema clásico de formas de obligarse y sus acciones correspondientes. Justiniano, siguiendo una simplificación que aparecía ya en Gayo, considera que todo convenio obligacional es un "contrato", por lo que distingue las obligaciones de contrato de las de delito, y luego divide las que no entran en ninguno de los dos conceptos en "cuasi-contractuales" o "cuasi-delictuales", según la mayor similitud con uno u otro grupo". El profesor Guillermo Floris enseña que Gayo sostenía, todavía a mediados del siglo II, en sus Instituciones, que todas las obligaciones nacían de contratos o de delitos. Pero en el Digesto, al citarse nuevamente a Gayo, en relación con este tema, se le hace añadir - por interpolación- una nueva fuente de obligaciones, un poco nebulosa: variae causarum figurae ${ }^{8-9}$.

Posteriormente, siguiendo al profesor Manuel García Garrido, en los intérpretes medievales y modernos han tenido gran influencia las clasi-

\footnotetext{
6 VON TUHR: Tratado de las obligaciones. Traducción de W. Roces. Tomo Primero, Editorial Reus S.A., Madrid, 1999, p. 31

D'ORs, Álvaro: Derecho Privado Romano, Ediciones Universidad de Navarra S.A., Pamplona, 1997, p. 420

8 FloRis Magadant, Guillermo: El Derecho Privado Romano, Editorial Esfinge, Naucalpán, México, 1991, p. 315

9 En efecto, siguiendo al profesor GARCía GARrido, Manuel: Derecho Privado Romano. Casos, acciones, instituciones, Editorial Dykinson, Madrid, 1998, pp. 476, 477 y 478, Gayo afirmaba: "Pasemos ahora a las obligaciones, cuya principal división abarca dos clases: pues toda obligación nace o de un contrato o de un delito". Posteriormente, en el tratado postclásico de la jurisprudencia de las cosas, atribuida a Gayo, se da una nueva clasificación de las causas de las obligaciones: "Las obligaciones nacen sea de un contrato, sea de un maleficio, sea de cierto derecho, por distintos tipos de causas". Gayo, res cott. D 44.7.1. pr. Las causas de las relaciones obligatorias resultaban así repartidas en una tercera división, junto al contrato y al maleficio o delito, que se comprende con la denominación genérica de "distintos tipos de causas".
} 
ficaciones escolásticas de los libros de Instituciones de Gayo y de Justiniano, hasta el punto en que ha sido decisiva en la moderna sistemática de las obligaciones de la doctrina y de los códigos civiles ${ }^{10}$. Así, Justiniano, de acuerdo con su concepción de que no hay contrato sin consentimiento, dividió las obligaciones contractuales en dos categorías: obligaciones de contrato y obligaciones como de contrato (quasi ex contractu), incluyendo en esta última los negocios no convencionales. El profesor García Garrido afirma que un deseo de simetría le llevó a distinguir entre obligaciones derivadas de delito y las que venían como de delito, pero comenta que su distinción fue arbitraria, por cuanto carecía de una concepción de delito"1. Finalmente, señala: "Los intérpretes griegos del derecho justinianeo cambiaron ligeramente la nomenclatura de la cuatripartición, al decir que las obligaciones derivan del contrato o cuasicontrato, del delito o cuasidelito. Esta terminología es la que ha pasado a la sistemática moderna"12.

Nuestro Código Civil, siguiendo la tradición del Código de Napoleón, adoptó esta clasificación y distingue así cinco fuentes de las obligaciones, a saber: el Contrato; el cuasicontrato, el delito, el cuasidelito y la Ley. El artículo 1437 es el que se encarga de enumerar las fuentes de las obligaciones en nuestro Derecho Civil: "Las obligaciones nacen, ya del concurso real de las voluntades de dos o más personas, como en los contratos o convenciones; Ya de un becho voluntario de la persona que se obliga, como en la aceptación de una berencia o legado y en todos los cuasicontratos; ya a consecuencia de un becho que ha inferido injuria o daño a otra persona, como en los delitos y cuasidelitos; Ya por disposición de la ley, como entre los padres y los hijos sujetos a patria potestad". Por su parte el artículo 2284 versa: "Las obligaciones que se contraen sin convención, nacen o de la ley, o del becho voluntario de una de las partes. Las que nacen de la ley se expresan en ella. Si el becho de que nacen es lícito, constituyen un cuasicontrato. Si el hecho es ilícito y cometido con intención de dañar, constituye un delito. Si el becho es culpable pero cometido sin intención de dañar constituye un cuasidelito. En este título se trata solamente los cuasicontratos"13.

Sin duda alguna, la fuente más importante de las obligaciones, es el contrato. Este, tradicionalmente se ha entendido como generador de derechos personales y no de derecho reales. Siguiendo al profesor Jorge López, el concepto habitualmente aceptado del contrato reposa en el acuerdo de voluntades de las partes. Desde este punto de vista, el con-

10 GARCIA GARRIDO: (n. 9), p. 476.

11 El profesor FLORIS (n. 8), p. 315, indica: "Luego, Justiniano, con su veneración mística por el número cuatro, amplió una vez más la lista de las fuentes de las obligaciones, señalando cuatro: contratos, delitos, cuasicontratos y cuasidelitos".

12 García Garrido: (n 9), p. 480.

13 De similar forma, el artículo 1089 del Código Civil español prescribe: "Las obligaciones nacen de la ley, de los contratos y cuasicontratos, $y$ de los actos y omisiones ilícitos o en que intervenga cualquier género de culpa o negligencia". 
trato es el acuerdo de voluntades o convención que crea obligaciones. Afirma el profesor López: "El querer o intención de las partes domina, así, la formación, génesis o nacimiento del contrato y también sus efectos y consecuencias" ${ }^{14}$. De este modo, el concepto tradicional del contrato reposa en el dogma de la autonomía de la voluntad, consagrado en el Código Civil francés y de allí que se expandiera a los códigos latinoamericanos. Cueto afirma que en el derecho civil de origen romanista no existen mayores dudas acerca del fundamento del contrato. Este es la expresión de la libre voluntad de dos o más personas capaces ${ }^{15}$.

En el sistema del common law, en cambio, prevalece una concepción distinta, de naturaleza objetiva. Cueto indica: "En la tradición del derecho civil romanista (...) el contrato es el producto de esas voluntades $y$, por ello, dudas acerca de su significado deben ser superadas procurando desentrañar lo querido por cada una de las partes contratantes (...) Por razones primordialmente bistóricas, cuyo relato excede el propósito de este trabajo, ha existido una fuerte resistencia en el derecho anglosajón y también en el norteamericano, a reconocer a la voluntad sin más, la aptitud de crear obligaciones para cuyo cumplimiento las partes contratantes pudieran acudir a los jueces pidiéndoles el auxilio del aparato coercitivo del Estado a los fines de lograr el cumplimiento de la obligación creada por ellas o la indemnización de los perjuicio ocasionados por su incumplimiento. Además del acuerdo de voluntades (meeting of the minds) se necesitaban ciertos bechos adicionales que justificaran la movilización de órganos de la comunidad para hacer cumplir (to enforce) lo prometido por los contratantes"16. El profesor Jorge López explica: "El contrato tiene en Derecho inglés un profundo carácter formal y ello se materializa, ya sea a través de lo que nosotros calificamos como formalidades contractuales, ya sea a través de una forma peculiar: la consideration (...) La ley inglesa solo reconoce dos tipos de contratos: the contract Ander seal and the simple contract. La regla general es el contrato común. La excepción, el contrato bajo sello. El contrato común (simple contract o parol contract) necesita por fuerza una consideration La voluntad desnuda o a secas de las partes jamás es vinculante por sí sola"17.

Nuestra doctrina, siguiendo la autoridad de Pothier y la escuela francesa, siempre ha distinguido entre convenciones y contratos, tomando en cuenta el contenido de ambos. La convención, como se sabe, es el acto jurídico bilateral cuyo objeto es la creación, modificación, transferencia o extinción de un derecho u obligación. El contrato, como categoría o

\footnotetext{
14 López Santa María, Jorge: Los contratos. Parte general. Tomo I, Editorial Jurídica de Chile, Santiago, 1998, p. 15.

15 Cueto Rúa, Julio: Una concepción objetiva del contrato. El caso del "Common Law", en A.A. V.V., Contratos. Ediciones La Roca, Buenos Aires, 1989, p. 31.

16 Cueto: (n. 15), p. 32. Una completa exposición de esta materia y la evolución del common law se encuentra en LÓPEZ SANTA MARíA: (n 14), pp. 74 y siguientes.

17 LÓpez SANTA María: (n 14), p. 79.
} 
especie de la convención, es el acto jurídico bilateral creador de derechos y obligaciones. Larroumet, refiriéndose a la noción de contrato, dice que: "es un acto jurídico que tiene por objeto crear un vínculo de obligación entre acreedor y deudor (...) En efecto, en una concepción restrictiva, el contrato es una convención que tiene por objeto crear un vínculo de obligación entre un acreedor y un deudor ${ }^{18}$. Por ello se define el contrato comúnmente como la convención destinada específicamente a crear obligaciones, es decir, el acuerdo de las voluntades de dos o más partes con el objeto de crear entre ellas una o más obligaciones y la convención es el acuerdo de las voluntades de dos o más partes dirigido a crear, modificar, regular o extinguir entre ellas una relación jurídica. Los autores chilenos coinciden, sin embargo, que esta distinción puede hacerse en ciencia pura, por cuanto esta no tiene importancia práctica porque las reglas se aplican por igual al contrato obligacional como a los demás actos jurídicos bilaterales ${ }^{19}$.

El Código Civil define el contrato en su artículo 1438, el cual dispone: "Contrato o convención es un acto por el cual una parte se obliga para con otra a dar, hacer o no hacer alguna cosa. Cada parte puede ser una o muchas personas". Se ha criticado la definición del Código Civil señalando que confunde el contrato y la convención, términos que se encontrarían en relación género-especie. Sin embargo, como muy bien indica el profesor Abeliuk, la crítica es cierta, a medias. En derecho comparado, contrato y convención son términos sinónimos. Cita, por ejemplo, el artículo 1321 del Código Civil italiano, que dispone: "El contrato es el acuerdo de dos o más partes para constituir, regular o extinguir entre sí una relación jurídica patrimonial" 20 .

18 Citado por Rodríguez Grez, Pablo: Responsabilidad contractual, Editorial Jurídica de Chile, Santiago, 2004, p. 32.

19 En este sentido, verbi gracia, CORRAL TALCCIANI, Hernán. La definición de contrato en el Código Civil Chileno y su recepción doctrinal. Comparación con el sistema francés, en Documentos de Trabajo. Universidad de los Andes. $\mathrm{N}^{\circ} 43$, p. 19. Este trabajo se publicó posteriormente en A.A.V.v. Derecho de los contratos, Facultad de Derecho de la Universidad de los Andes, Cuadernos de extensión jurídica. 2002. ALESSANDRI RODRÍGUEZ, Arturo: De los contratos, Editorial Jurídica de Chile, 1993, p. 4. Somarriva, Manuel. Alessandri, Arturo y VODANOviC, Antonio: Tratado de las Obligaciones. De las obligaciones en general y sus diversas clases, Editorial Jurídica de Chile, 2001, p. 46. RODRf́GueZ: (n 18), p. 32 indica: "Aunque la distinción entre convención y contrato no tiene ningún interés en la práctica, se considera, generalmente, que la primera es el género al cual pertenece el segundo, que aparece como especie". AbeliuK: (n 2), p. 53. En igual sentido, LÓPEZ SANTA MAŔ́a: (n 14), p. 17, quien va a admitir la crítica solo por razones didácticas, pero advierte que en el Derecho comparado son numerosos los ordenamientos que identifican contrato y convención. En España, por ejemplo, el profesor PUIG BRUTAU, José: Fundamentos de Derecho Civil, Editorial Bosch, Barcelona, 1983, pp. 9 y 10, sostiene: "En sentido amplio, pero más preciso, el contrato es toda convención o acuerdo de voluntades por el que se crean, modifican o extinguen relaciones jurídicas de contenido patrimonial y que se hayan al alcance de la autonomía de la voluntad. Con sentido más estricto la palabra contrato bace referencia al acuerdo de voluntades de dos o más partes por el que se crean, modifican o extinguen relaciones pertenecientes al derecho de obligaciones". 
Interesante resulta señalar que los primeros proyectos del Código Civil definían el contrato, siguiendo la tradición del Derecho natural racionalista y la del Código Civil francés, derechamente como una convención. Se piensa que la asimilación de los conceptos y la inclusión de una categoría más amplia -actos- (contrato o convención es un acto dice el artículo 1438 del actual texto) no se debe a un error del legislador, sino a la inclusión en nuestro sistema de la teoría alemana del negocio jurídico, introducida por Savigny. En efecto, como explica el profesor Corral, el Código de Napoleón reglamentó los contratos como modelo paradigmático de todas las actuaciones jurídicas privadas. Por eso el título III del Libro III se denomina "Des contrats ou des obligationes conventionnelles en général". En los capítulos I y II de este título se contiene una regulación del concepto de contrato, sus clasificaciones y condiciones de validez: capacidad, objeto y causa. Frente a esta forma de normar las situaciones jurídicas se presenta la doctrina alemana, que trataba de buscar un instrumento técnico más genérico que el de contrato para englobar las formas de relación entre los otros dos macroconceptos civilísticos: las personas y las cosas. Esta categoría es la del acto jurídico o negocio jurídico ${ }^{21}$.

Nuestro Código Civil buscó una tercera vía en su regulación. A este respecto, el profesor Corral señala: "...Bello pretendió forjar una fórmula sincrética entre la doctrina del contrato que le era más familiar (a través del Código Civil francés y sus principales comentaristas), y por la entonces novedosa teoría de la declaración de voluntad que planteaba Savigny en su Sistema de Derecho Romano Actual". Más delante, agrega: "El giro hacia la idea del negocio jurídico aparece en el llamado Proyecto Inédito (resultado de la revisión del texto de 1853), en el cual, a los preceptos ya afinados sobre la base de la figura del contrato, se superpone ahora una categoría más amplia: la del "acto voluntario", que sigue sin embargo dentro del Libro IV, el que continúa con el epígrafe "De las obligaciones en general y de los contratos" 22 .

En la sistemática de nuestro ordenamiento jurídico el contrato es un instituto jurídico que solo puede crear derechos personales, no reales, por cuanto en su virtud solo se adquiere el título de una respectiva cosa, pero para adquirir el dominio sobre esta, se necesita un modo de adquirir establecido por la ley, el cual será en los contratos traslaticios de dominio, la tradición, de tal suerte que reunidos ambos (título y modo), nace el derecho real de domino. El mismo sistema se aplicaría a los demás derechos reales. Este sistema se encuentra establecido por un conjunto de disposiciones de nuestro Código. A propósito de la compraventa, el artículo 1793 dispone que este es un contrato por el cual una de las

\footnotetext{
21 CORRAL: (n 20), p. 71.

22 CORRAL: (n 20), p. 4.
} 
partes se sujeta a dar una cosa a favor de otro, mientras que el artículo 1824 prescribe que las obligaciones del vendedor se reducen a la entrega o tradición de la cosa y a la entrega, agregando que la tradición se sujeta a las reglas del Título VI del Libro II.

Por su parte, los artículos 682 y 683 regulan los efectos de la tradición. La tradición genera efectos distintos, dependiendo si el tradente es o no dueño de la cosa. Si este es dueño, la tradición operará como modo de adquirir y transferirá el dominio de la cosa. Si no lo es, constituye en poseedor al adquirente, de manera que este pueda ganarla por prescripción. Estas normas se ven complementadas por el artículo 1815, que prescribe que la venta de cosa ajena vale, sin perjuicio de los derechos del verdadero dueño y, especialmente, con la obligación de saneamiento de la evicción que se traduce en amparar al comprador en la posesión pacífica y tranquila de la cosa, defenderlo de las acciones intentadas por terceros e indemnizar al comprador si esta resulta evicta (arts 1837 y 1843 y siguientes). Este conjunto de disposiciones permite sostener que el vendedor satisface cuando constituye en poseedor al comprador, de manera que este pueda ganar la cosa por prescripción y la expresión dar o entregar que utilizan los artículos 1793 y 1824 se refieren a los distintos efectos de la tradición.

Sin embargo, en este artículo se intentará demostrar que para un determinado número de casos, las reglas precedentemente expuestas no se aplican, porque los contratos generan efectos reales. Es reconocido que los ordenamientos que siguen el sistema romano, como el nuestro, establecen ciertas excepciones al principio de la dualidad título-modo, por exigencias del tráfico jurídico. Por el contrario, el sistema francés, del efecto real del contrato, también debe hacer cierta excepción a sus reglas para explicar los contratos reales ${ }^{23}$. Ello ocurre en dos hipótesis bastante precisas, que pasaremos a analizar. En los casos de tradición de bienes muebles denominadas tradición de breve mano y la denominada constituto posesorio, reguladas en el $\mathrm{N}^{\circ} 5$ del artículo 684 del Código Civil ${ }^{24}$.

23 Sobre el particular, Peñallillo Arévalo, Daniel: Los bienes. La propiedad y otros derechos reales, Editorial Jurídica de Chile. Colección de manuales jurídicos, Santiago, 2002, pP. 111 y 112. ENNECCERUS, Ludwig. KIPP, Theodor. WOLF, Martín: Tratado de Derecho Civil. Tomo I. Vol. 1. Derecho de cosas, Editorial Bosch, Barcelona, 1971, p. 426.

Aún pueden encontrarse otras situaciones en las que los contratos pueden tener efectos reales. El profesor PEÑAILILlO: (n 23), pp. 113, 214 y 215, estima que esta situación puede presentarse en la cesión de créditos no documentados. Para VIAL DEL Río, Víctor: La tradición y la prescripción adquisitiva como modo de adquirir el dominio, Ediciones $\mathrm{P}$. Universidad Católica de Chile, Santiago, 2003, p. 29, dicho efecto real puede existir en el mutuo, en el cual, junto con el perfeccionamiento del contrato se produce la tradición. Lo mismo opina, nuevamente Peñailillo: (n 23), p. 139, quien señala: 2 La técnica del contrato real, abandonada ya por algunas legislaciones, ocasiona entre nosotros un conflicto con el sistema antes descrito; en efecto, como estos contratos se perfeccionan por la entrega de la cosa (art. 


\section{LA FORMAS DE TRADICIÓN DEL NUMERAL 5 DEL ARTÍCULO 684 DEL CÓDIGo CIVIL}

Como se sabe, el artículo 684 del Código Civil regula las formas de tradición de los bienes muebles. Para algunos autores, todos los casos señalados en el artículo 684 constituyen formas fictas ${ }^{25}$. Otros, en cambio, consideran tradición real a la del número 1 del artículo 684. En tanto, las cuatro restantes serían casos de tradiciones fictas, agrupándolas en tradición simbólica (artículo $684 \mathrm{~N}^{\circ} \mathrm{s} 3$ y 4), tradición de larga mano (artículo $684 \mathrm{~N}^{\circ}$ 2), la tradición de breve mano (artículo $684 \mathrm{~N}^{\circ}$ 5) y la cláusula de constituto (artículo $\left.684 \mathrm{~N}^{\circ} 5\right)^{26}$.

Los casos que vamos a analizar son el constitutum possessorio y la tradición de brevi manu. En ambas se evita el doble movimiento material. En la llamada tradición de breve mano, la tradición se produce simplemente por la celebración de un contrato de compraventa, donación u otro título traslaticio de dominio conferido en favor del mero tenedor. Con esta forma de tradición, como señala el profesor Peñailillo se evita una doble entrega, consistente en restituir el bien objeto de la mera tenencia para que luego el dueño efectúe la tradición, entregando nuevamente la cosa al mero tenedor, ahora constituido en poseedor ${ }^{27}$. En el caso del constitutum possessorio el dueño y poseedor de la cosa, en virtud de un contrato de mera tenencia, pasa a detentar la cosa como mero tenedor. Como en el caso anterior, se evita la doble entrega, consistente en que el tradente entregara la cosa primero y luego esta se le restituyera al tridente, ahora bajo el título de mera tenencia ${ }^{28}$.

A nuestro juicio, las formas de tradición del artículo $684 \mathrm{~N}^{\circ} 5$ otorgan un efecto real al contrato, debido a que el simple pacto es equiparado a la tradición. Así lo ha reconocido también la doctrina nacional.

1443), y en algunos de ellos, como en el mutuo, esa entrega es tradición, porque transfiere el dominio de lo entregado (art. 2197), surge la interrogante de saber cuál es el título de esa tradición, toda vez que antes de la entrega no hay contrato". Otro tanto puede decirse de la prenda, en el sentido siguiente. Si bien se trata de un contrato real que se perfecciona por la mera entrega de la cosa al acreedor, tratándose de un título de mera tenencia, autores como Somarriva Undurraga, Manuel. Tratado de las cauciones. Editorial Jurídica ConoSur. $1^{\text {a }}$ Edición. Santiago, pp. 244 y 245 , sostienen que a la vez esa entrega constituyen la tradición del derecho real de prenda, que nacería al mismo tiempo de perfeccionarse el contrato.

25 En este sentido, Peñailillo: (n 23), p. 149.

26 En este sentido, AlESSANDri RodríGueZ, Arturo. Somarriva Undurraga, Manuel. VodANOvic H., Antonio: Tratado de los derechos reales, Editorial Jurídica de Chile, Santiago, 2001, pp. 212 y 213 . En el mismo sentido, ROZAS VIAL, Fernando: Los bienes, Editorial Jurídica ConoSur Limitada, Santiago, 1998, p. 172. PeÑaIlillo: (n 23), p. 150. En el mismo sentido Alessandri, Somarriva y VODANOVIC: (n 26), p. 213. 
Así, por ejemplo Peñailillo indica: "Ya en la época del Derecho justinianeo $y$ por la fuerza de las cosas, que en muchos casos imposibilita una entrega mano a mano, se hallaban en pleno desarrollo las tradiciones fictas o simbólicas, que fueron reemplazando en gran medida la entrega real, incluso en objetos en que esta era posible. Este desenvolvimiento constituye una suerte de desmaterialización de la tradición (llamado también proceso de espiritualización), que resultó trascendental; no cesó en el futuro y culminó a fines del siglo XVIII en un verdadero efecto real del contrato, por lo que el solo convenio transfiere el dominio, consagrado, como se ha dicho, en el Código francés y de abí seguido por varios otros (...) Aun cuando se recordará oportunamente, puede anticiparse que precisamente en algunas de estas tradiciones fictas se observa, entre nosotros, un notable debilitamiento del sistema, que llega a acercarse mucho, con ellas, al otro, de transferencia por el solo contrato"29.

En el derecho comparado se sostienen opiniones similares. Por ejemplo, los profesores Diez Picazo y Gullón, comentando la doctrina de la transmisión consensual del dominio, señalan que: "Al lado de la traditio real, se admitieron muy pronto formas de tradición simbólica y aún de tradición ficticia -tradittio brevi manu, constitutum possessorium, etc.-, de tal manera que se puede decir que la traditio conservaba su valor pero en la práctica era la voluntad de las partes lo que determinaba la tradición"30. Para Enneccerus, Kipp y Wolf: "Mientras otros derechos se conforman con el simple acuerdo y prescinden de la necesidad de una tradición, el moderno derecho alemán se atiene por principio al requisito de la entrega. Por lo demás, este principio de la tradición está afectado de numerosas e importantes excepciones, en las que, para simplificar el tráfico jurídico, o bien se substituye la entrega por un simple acuerdo de voluntades (así en el caso del constituto posesorio, y en la cesión de la reivindicatoria; of sobre este punto infra E67) o bien desaparece la obligación de entrega sin sustitutivo (como en el caso de la tradición brevi manu...)"31. Y Hedeman, refiriéndose a la tradición de bree mano, indica: "El adquirente está ya en situación de ejercer el poder de becho sobre la cosa, pero sin ser todavía poseedor. Entonces basta un acuerdo con el anterior poseedor, es decir, un proceso puramente volitivo, para convertir en lo sucesivo al adquirente en verdadero poseedor" 32.

PeÑaILILlo: (n 23), p. 147. Otros autores, en cambio, como Alessandri, SOMARriva y VODANOVIC: (n 26), p. 133 y 134; 212 y 213 guardan silencio sobre el punto, pero al tratar la tradición de breve mano reconocen que desde el instante de conclusión del contrato, se entiende hecha la tradición. Para RozAS: (n 26), pp. 28 y 29, en los casos comentados la ley finge directamente la tradición, pues no puede desconocerse que la calidad jurídica, es decir, la posición jurídica en relación con la cosa, cambia por la celebración del contrato.

30 Diez PICAzo, Luis. Gullón, Antonio: Sistema de Derecho Civil. Volumen III. Derecho de cosas y Derecho inmobiliario Registral, Editorial Reus, Madrid, 2000, p. 65.

ENNECCERUS, KIPP. Y WOLFF: (n 23), p. 426.

32 Hedeman: Tratado de derecho civil. Tomo II. Derechos reales, Editorial Revista de Derecho Privado, Madrid, 1955, p. 63. 
Es cierto que nuestro Código reguló el constitutum possessorium y la traditio brevi manu como especies de tradición, pero nuestra doctrina reconoce que se trata de formas fictas, es decir, formas que la ley las asimila a la tradición, que las declara tradición, pero que en el plano real no pueden separarse del título o simple negocio causal. Como señalan Blas Pérez y José Alguer en el constituto posesorio -reconocido en los artículos 1462, 1463 y 1464 del Código Civil español- hay una aproximación al efecto real del contrato, por cuanto en el orden de la ficción simplificadora, no solo elimina la necesidad de tradición real, sino el acuerdo de transferencia, que viene reabsorbido en el contrato de compraventa ${ }^{33}$. Con ello queremos señalar que nuestro sistema, no obstante seguir la doctrina romana de la dualidad, para ciertos ámbitos, tratándose de bienes muebles, en los que el título traslaticio es consensual y la tradición tampoco reviste formalidad alguna, en los hechos, sustantivamente, terminan confundiéndose en una sola operación. En los casos arriba citados, debido a las exigencias del tráfico jurídico y la realidad antes anotada, la tradición queda incorporada, es decir, subsumida en el convenio obligatorio, en el mero título, sin que exista un acto posterior de publicidad que revele una actuación, un acto o una conducta de transferir. El acuerdo traslaticio queda manifestado y reflejado en el contrato obligatorio, en el título. De allí que sostengamos que, aunque la ley la denomina tradición, en verdad se trata a lo menos de una atenuación a la estructura del título-modo y, desde una perspectiva lógica, el otorgamiento de efecto real al mero contrato.

\section{LA CONSTITUCIÓN DEL DERECHO REAL DE HIPOTECA ¿EFECTO REAL DEL CONTRATO DE HIPOTECA?}

\section{Concepto y características que se atribuyen a la hipoteca como derecho real}

La hipoteca es uno de los más importantes contratos del tráfico jurídico y presenta múltiples implicancias en los ámbitos de los derechos reales, las obligaciones y los contratos. En cada una de dichas ramas se aborda un aspecto del instituto. Esta múltiple perspectiva es abordada por el profesor Somarriva quien explica la institución desde la perspectiva de la caución. Se detiene en el análisis del derecho de prenda general -consagrado en nuestro Código Civil, e el artículo 2465-, para luego señalar que las cauciones suplen las deficiencias de la garantía general del acreedor ${ }^{34}$.

34 SOMARRIVA: (n 24), p. 7 y 8 . Esta es la misma perspectiva desde la cual analiza la institución Diez Duarte, Raúl: La Hipoteca en el Código Civil chileno, Pacsed editores, Santiago, 1991. 
Como caución, la hipoteca aparece regulada en el artículo 46 del Código Civil, la que define precisamente caución como toda obligación que se contrae para seguridad de una obligación propia o ajena. Luego, se distingue entre cauciones personales y reales. Entre las cauciones personales se ubica la fianza, la cláusula penal y la solidaridad pasiva. Son personales por cuanto, se suman patrimonios para responder en caso de insatisfacción del crédito. En cuanto a las cauciones reales, estas afectan un bien determinado, sea mueble e inmueble y otorgan al acreedor un derecho real sobre la cosa. Son la prenda y la hipoteca. De ahí que el artículo 577 los mencione como derechos reales y queden sujetos, en principio, a las mismas normas de adquisición, modificación y extinción del dominio, de acuerdo con los artículos 670, inciso segundo (para el caso de la tradición); artículo 686, inciso segundo (para la tradición de los derechos reales que recaen sobre inmuebles); 891 (para la acción reivindicatoria); 2498, 2505 y 2512, para la prescripción adquisitiva.

Sin embargo, el Código Civil, siguiendo su modelo francés, no reguló la hipoteca, ni la prenda en el libro dedicado a los derechos reales, sino que ubicó su regulación en el libro IV, Títulos XXXVII y XXXVIII, es decir, entre los contratos. Como señala el profesor Somarriva: "Si la bipoteca es un derecho real, quizás hubiera sido más lógico que el legislador, tal como lo hacen los Códigos más modernos, se bubiera ocupado de ella al referirse a esta clase de derechos, en el libro II, por ejemplo a continuación de las servidumbres. Pero la ubicación que tiene dentro de los contratos se justifica tanto por una razón histórica ya que esa misma ubicación tiene en el Código francés, cuanto porque en el Código Civil la bipoteca es siempre de origen contractual..."35.

El Código Civil definió la hipoteca en el artículo 2407: "La bipoteca es un derecho de prenda, constituido sobre inmuebles que no dejan por eso de permanecer en poder del deudor". La definición es sumamente criticada por la doctrina, la que prefiere enfocar su concepto desde la perspectiva del derecho real, toda vez que nuestro sistema no solo reconoce la existencia de hipotecas voluntarias, sino también legales. Así, por ejemplo, Fernando Alessandri define la hipoteca como: "un derecho real que se confiere a un acreedor sobre un inmueble, de cuya posesión no es privado su dueño, para asegurar el cumplimiento de una obligación principal y en virtud del cual el acreedor, al vencimiento de dicha obligación, puede pedir que la finca gravada, en cualesquiera manos en que se encuentre, se venda en pública subasta y se le pague con su producido con preferencia a todo acreedor". Y agrega, para explicar la definición: "No bemos definido la bipoteca tomando en cuenta el aspecto contractual que ella tiene en el C. C.; porque aun cuando la bipoteca, por regla general proviene de la convención, no es ménos (sic) cierto que, según el C.P.C., también 
nace de ella por el ministerio de la ley"36. Somarriva la define como: "el derecho real que recae sobre un inmueble que, permaneciendo en poder del que lo constituye, da derecho al acreedor para perseguirlo en manos de quien se encuentre $y$ de pagarse preferentemente del producido de la subasta"37-38.

Entrando de lleno en la hipótesis de este apartado, en cuanto derecho real, la dogmática chilena le asigna dos características al derecho real de hipoteca: a) constituye una limitación al dominio; b) es un principio de enajenación. Analizaremos brevemente la exposición de ambas características.

Señala el profesor Somarriva que a pesar de no encontrarse enumerado entre las limitaciones al dominio del artículo 732 del Código Civil, resulta evidente dicho carácter, pues el propietario del bien raíz no puede ejercer el dominio de manera absoluta; no puede destruir el inmueble, ni gozar de él en términos que lesionen los derechos del acreedor hipotecario, en cuyo caso recibe aplicación el artículo 2427 del Código Civil ${ }^{39}$. De esta manera, el profesor Somarriva distingue dos períodos en cuanto a los efectos de la hipoteca con respecto al dueño del inmueble hipotecado. Antes que el acreedor ejercite el derecho de hipoteca el dueño conserva las facultades inherentes al dominio, esto es, la de usar, gozar y dispone del inmueble gravado. En cuanto a la disposición o gravamen del inmueble, hay expresa autorización en el artículo 2415, que incluso prohíbe todo pacto que embarace o limite la facultad de disposición. Sin embargo, considera que no es posible constituir otros gravámenes sobre el inmueble hipotecado, porque con ello puede afectar el derecho del acreedor hipotecario ${ }^{40}$.

AlesSANDRI, Fernando: Memoria de prueba, Universidad de Chile, Santiago, 1919, pp. 3 y 4. SOMARRIVA: (n 24), p. 309, agregando igualmente que la definición arranca desde la óptica del derecho real, debido a que esta no solo nace de la voluntad de las partes, sino también de la ley. Una opinión similar se encuentra en MEZA BARros, Ramón: Manual de Derecho Civil. De las fuentes de las obligaciones. Tomo II, Editorial Jurídica de Chile, Colección de manuales jurídicos, 1960, p. 162.

Como señala el propio profesor SOMARRIVA: (n 24), pp. 202, 203 y 308, el Código, al definir la hipoteca como un derecho de prenda no ha incurrido en un error, pues tanto la prenda como la hipoteca tienen un origen común y no presentan diferencias sustanciales, pues la entrega al acreedor, por un lado y los bienes sobre las cuales recaen constituirían diferencias de carácter secundarias. Sobre el particular puede consultarse LASARTE Álvarez, Carlos: Principios de derecho civil. Tomo V. Propiedad y derechos reales. Editorial Trivium. Madrid. 2001, p. 73; ENNECCERUS, KIPP. y WOLF: (n 23), pp. 175 y 176. SOMARRIVA: (n 24), pp. 325 y 415. Coincide ALESSANDRI: (n 36), pp. 12 y 13, quien con similares argumentos llega a sostener que se trata de una limitación al dominio, tomando como base el mismo artículo 2427. Les sigue Diez: (n 34), pp. 239 y ss.

SOMARRIVA: (n 24) p. 416. Sin embargo, la posición del distinguido profesor no es clara, por cuanto primero indica que le estaría vedado al deudor hipotecario gravar el bien con otro derecho real distinto de la hipoteca, pero luego, citando la autoridad de Josserand señala que de constituirse dichos gravámenes, varias disposiciones del Código Civil, entre ellas los artículos 1366, 2438 y 1962 indicarían que tales gravámenes, incluso los personales, no serían oponibles para el acreedor hipotecario. 
De otra parte, la constitución de hipoteca tampoco es obstáculo para que el propietario use y goce del inmueble gravado y agrega: "Podrá, en consecuencia, darlo en arrendamiento, percibir y enajenar los frutos naturales que produjere, enajenar los inmuebles por adberencia, pero siempre que esta enajenación represente la explotación normal del inmueble bipotecado". Finalmente, si el inmueble se pierde o deteriora en términos de no ser suficiente para la seguridad de la deuda, se ortiga un derecho alternativo al acreedor para exigir el mejoramiento de la hipoteca, la constitución de una equivalente o el cumplimiento de la deuda, conforme al artículo 2427. Esta es, precisamente, la norma que permite afirmar el carácter de limitación al dominio. Somarriva sostiene que la norma tiene tal amplitud que opera sea que el deterioro o pérdida sea fortuito o debido a culpa o dolo del propietario; o con independencia de la causa de la pérdida, salvo que existiera al tiempo de la celebración de la hipoteca o que era previsible su pérdida de valor o que el deterioro provenga de la depreciación normal del bien. Por último, si se trata de deterioro, este debe ser de tal magnitud que haga la cosa inapta para servir de garantía ${ }^{41}$.

Después que el acreedor ejercita la acción hipotecaria, embargando el bien, cesa la facultad del propietario de disponer y gozar del bien raíz. El embargo sobre la propiedad importa la nulidad absoluta de la enajenación, por objeto ilícito en atención a lo dispuesto en el artículo 1464 $\mathrm{N}^{\circ} 3$ del Código Civil (y, según algunos, también lo sería el contrato de compraventa, conforme al artículo 1810); además, el embargo privaría al deudor de la libre administración del bien, sin perjuicio que los artículos 2424 y 2403 el acreedor hipotecario tiene para hacerse pagar los mismos derechos que el acreedor prendario sobre la prenda y, en conformidad con la segunda, si la prenda ha dado frutos, el acreedor está facultado para imputarlos al pago de la deuda, dando cuenta de ellos y respondiendo del sobrante, si lo hubiere.

Una segunda característica que se asigna al derecho real de hipoteca, conectada con la anterior, consiste en que constituiría un principio de enajenación. El profesor Somarriva la explica así: "Si como acabamos de ver el propietario al gravar sus bienes con bipoteca se desprende de parte del dominio, es evidente que ella encierra un principio de enajenación, o, como decía Bello, una enajenación condicionada" 42 . Para Alessandri, la hipoteca presenta el carácter de desmembración del dominio e invoca como argumento el que la sentencia que priva al propietario del dominio de un inmueble hipotecacon hipoteca, se desprende de parte del dominio. Agrega: "Es evidente que la bipoteca encierra un principio de enajenación. Por eso, en doctrina pura, la bipoteca es una enajenación condicionada en caso que el acreedor bipotecario haga uso de los derechos propios de todo acreedor bipotecario". 
do, por evicción o resolución del derecho, no puede afectar la hipoteca si el acreedor hipotecario no ha sido citado al juicio, lo que podría explicarse porque el dueño no puede defender una parte de ese derecho que corresponde al acreedor hipotecario ${ }^{43}$.

\section{Las hipoteca como contrato. Su carácter solemne y el papel de la inscripción}

Estas características del derecho real de hipoteca y, especialmente la última, es decir, que la hipoteca importaría una desmembración del dominio, hace suponer a los autores que la inscripción en el Registro de Hipotecas y gravámenes, tratándose de la constitución de la hipoteca, juega el papel de tradición. Discuten los autores si además dicha inscripción constituye solemnidad del acto, de acuerdo al tenor del artículo 2410 del Código Civil, pero unánimemente se parte de la premisa que en la constitución de la hipoteca la inscripción juega el rol de tradición. Conforme al artículo 2409 la hipoteca debe otorgarse por escritura pública. Por su parte, el artículo 2410 del Código Civil prescribe: " $L a$ bipoteca deberá además ser inscrita en el Registro de Conservatorio; sin este requisito no tendrá valor alguno; ni se contará su fecha sino desde la inscripción".

Para el profesor Somarriva dicha inscripción solo juega el papel de tradición del derecho real de hipoteca. Sostiene que en la constitución del derecho de hipoteca hay igualmente tradición, pues todo derecho real en nuestro sistema requiere de un título. Además, invoca las características de desmembración de dominio y principio de enajenación que hemos analizado en el apartado precedente. Indica: "Sabido es que el dominio está constituido por la suma de los derechos reales, de manera entonces que al constituirse la bipoteca el propietario se está desprendiendo de este derecho, que se encontraba en su patrimonio digamos en estado latente, y lo traspasa al acreedor y de este modo aquel es el tridente y este el adquirente" ${ }^{4}$. Para Diez: "Sin duda, el derecho real de bipoteca se puede adquirir por tradición, porque el artículo 670 del Código Civil, después de definir la institución, en el inciso segundo agrega, que lo que se dice del dominio se extiende a todos los otros derechos reales y estos derechos reales están determinados en el artículo 577 (...) El título traslativo, que requiere toda tradición, en la constitución de la bipoteca, está representado por el contrato bipotecario (...) Por cierto, los efectos de la tradición, del derecho real de bipoteca son los mismo efectos generales de la tradición. Nos referimos, por ejemplo, si el tridente es el propietario de la finca bipotecada, el acreedor hipotecario adquiere el derecho real de bipoteca. En el caso contrario, la tradición no es modo de adquirir el derecho real de bipoteca, porque nadie puede transferir más derechos que los que tiene. En esta 
segunda bipótesis, el acreedor hipotecario solo pasaría a tener la posesión del derecho real de bipoteca y mediante esta posesión podrá llegar a adquirir este derecho por el modo llamado prescripción adquisitiva" 45 .

Fernando Alessandri concuerda en que la inscripción juega el papel de tradición, pero además le asigna el rol de solemnidad. En efecto, afirma que la inscripción está ajustada en cuanto todo derecho real exige un título y un modo de adquirir para el nacimiento de un derecho real e invoca el mensaje del Código, en cuanto exige inscripción tanto para la transferencia, como para la constitución de un derecho real y sostiene: "En consecuencia, esta inscripción que constituye la tradición del derecho, pasa a ser un elemento indispensable en el contrato mismo de bipoteca (...) Vemos, pues, en la legislación alemana que sirvió de modelo a nuestro Código Civil, se exija la inscripción y la intervención del funcionario judicial como requisitos indispensables para que la bipoteca valiera como tal no solo respecto de terceros, sino contra las partes mismas", de donde deduce que la inscripción constituye solemnidad y la ausencia de cualquiera de dichas solemnidades acarrea la nulidad de la hipoteca ${ }^{46}$. Este carácter de solemne ha sido combatido por Somarriva, quien invoca los artículos 2411 y 2413 , normas que contemplan la hipoteca constituida en país extranjero y la hipoteca sobre cosa futura. En ambos casos el contrato se encuentra perfecto con la escritura pública. Además, la mera escritura pública no produciría obligación alguna, en tanto no operara la inscripción, que constituiría perfeccionamiento del contrato y tradición, con lo que se privaría en algunos casos al acreedor de exigir el cumplimiento del contrato o la restitución de lo que hubiere dado o pagado en razón de él ${ }^{47}$.

\section{Nuestra hipótesis: la inscripción constitutiva no importa tradición}

En los párrafos siguientes argumentaremos en contra de la posición unánime de nuestra doctrina. Sostendremos que la inscripción no juega papel de tradición, sobre la base de dos premisas. La primera consiste en desestimar el pretendido carácter de desmembración del dominio que tendría la hipoteca. Sobre dicha base sostendremos que no existe tradición, al no ajustarse el acto constitutivo a la naturaleza y características de esta institución.

El carácter de limitación del dominio se concluye, como hemos visto, del artículo 2427 del Código Civil, en cuanto importaría una limi-

DiEZ: (n 34), p. 44. Discutiendo acerca de la hipoteca de cosa ajena, el profesor SomARRIVA: (n 24), p. 385, utiliza precisamente la prescripción adquisitiva como argumento para sostener que es posible hipotecar una cosa ajena, sin perjuicio de los derechos del verdadero dueño.

47 SOMARRIVA: (n 25), p. 344. 
tación a la facultad de abuso del propietario, en cuanto se afecten los derechos del acreedor hipotecario. Es por ello que el propietario no podría ni destruir, ni deteriorar la cosa en los términos estudiados. Por ello se le adjudica este carácter, a pesar de no encontrarse enumerado en el artículo 732 del Código. Luego, la doctrina va más lejos en la argumentación, sosteniendo que se trataría de una auténtica desmembración del dominio, toda vez que el propietario se desprendería precisamente de esas facultades de abuso a favor del acreedor hipotecario y se agrega, como hemos advertido, cuestiones diversas, como que se trataría de una enajenación condicionada, sujeta a que no se cumpliera con la obligación principal, llegando a sostenerse que este derecho -el de hipoteca- se encontraría latente en el derecho de dominio, siendo transferido por el propietario en el acto constitutivo.

Siguiendo a Salvat, la hipoteca no puede ser asimilada a las desmembraciones del dominio, porque se constituye con el fin único y exclusivo de dar al acreedor una garantía para el pago de su crédito, no teniendo intención el dueño del terreno de conferir al acreedor hipotecario facultades directas sobre la cosa. La prohibición de ejercer actos que disminuyan el valor del inmueble o la obligación de tolerar su venta en beneficio del acreedor, son la consecuencia lógica de la garantía dada al acreedor y agrega: "...no se desprende que las facultades inherentes al derecho de propiedad sean separadas de este y trasladadas, para su ejercicio actual e inmediato, como ocurre en las verdaderas desmembraciones" 48 . En este sentido, consideramos que ha existido confusión de categorías jurídicas que se encuentran en planos distintos. La hipoteca es, a la vez, contrato y derecho real. Como contrato genera derechos y obligaciones para las partes. Una de dichas obligaciones consiste, precisamente, en no afectar la cosa en términos de destruirla o deteriorarla. Es pues, una limitación en cuanto es impuesta por el contrato. Con el criterio sustentado por nuestra doctrina también importaría limitación al dominio, por ejemplo, un contrato de compra-

SAlVAT, Raimundo: Tratado de Derecho civil argentino. Derechos reales, Tipográfica Editora Argentina, Buenos Aires, 1960, p. 27. Para SOMARRIVA: (n 24), p. 325, la circunstancia de no tener relación directa con la cosa no puede descartar su carácter de limitación del dominio (aunque pensamos que quería referirse más bien al carácter de desmembración del dominio), toda vez que habría otros derechos reales, como las servidumbres negativas de no edificar más allá de cierta altura, respecto de las cuales nadie duda su carácter de desmembración. SALVAT, p. 27 señala, en relación al punto: "En cuanto a la comparación con la servidumbre de no edificar o de no pasar la altura convenida, debe tenerse presente que si en ella el duñ̃o del fundo dominante no ejerce facultad alguna inmediata sobre el fundo sirviente, es por tratarse de una servidumbre consistente en abstenerse del ejercicio de facultades que sin ella el propietario podría ejercer: no hay en este caso simple limitación, como en la bipoteca, sino que facultad de edificar o no edificar o de levantar o no levantar las construcciones a una altura cualquiera, se encuentra separada del conjunto de facultades inberentes al derecho de propiedad, en beneficio del fundo dominante". 
venta de especie o cuerpo cierto respecto del cual el vendedor no ha efectuado la entrega. El vendedor sigue siendo dueño, pues debe cumplir con la obligación de dar (efectuar la tradición, con los papeles que esta puede cumplir: transferir el dominio o constituir en poseedor). $\mathrm{Y}$ es evidente que, en este caso, sus facultades de uso y abuso, conforme al artículo 1548, están limitadas, pues no podrá destruir la cosa, toda vez que se le impone una obligación de conservación. Nadie ha sostenido que en tal caso hay desmembración del dominio ${ }^{49}$.

En suma, del carácter limitativo que pueda tener una relación real o personal o crediticia sobre el propietario de un bien determinado, no puede atribuírsele inmediatamente el carácter de desmembración del dominio, para luego sostener la tradición en la constitución de gravámenes. Además, las nociones de limitación de dominio y de desmembración son contrapuestas, obedecen a dos concepciones distintas del dominio y no pueden utilizarse de manera yuxtapuesta para sostener, desde ahí, la tradición. Como explican los profesores Diez Picazo y Gullón: "La doctrina tradicional ha buscado, a veces afanosamente, una explicación a esta formación de los derechos reales a expensas de la propiedad. Muy a grandes trazos se puede decir que para dar esta explicación existen dos teorías, a las que se puede llamar, respectivamente, teoría de la desmembración y teoría del gravamen o de la carga. Para la primera concepción la propiedad es una suma o baz de facultades particulares y distintas que aparecen de algún modo yuxtapuestas. En este sentido, la constitución del derecho real limitado desmembra el dominio, pues separa o destaca una de esas facultades, que se transfiere a otra persona y se transforma en derecho real autónomo. La teoría de la carga o del gravamen prefiere concebir la propiedad como un conjunto unitario e indivisible, cuyas facultades no se separan nunca de ella, sino que permanecen siempre dentro, si bien comprimidas, limitadas e incluso temporalmente imposibilitadas en su ejercicio" 50 .

Es por ello que la doctrina más moderna prefiere comprender la categoría de los derechos reales limitados bajo el concepto de derecho sobre cosa ajena, distinguiéndose en cuanto a su función económica entre derechos reales de goce o disfrute y derechos reales de valor. Los primeros permiten a sus titular la utilización o explotación, total o parcial de un bien ajeno, así como, en algunos casos, la adquisición de frutos. En esta categoría se encuentran el usufructo, el uso y habitación y la servidumbre. Por su parte, los derechos de realización de valor otorgan a su titular

\footnotetext{
49 Algo similar sostienen DIEZ PICAZo y Gullón: (n 30), p. 383 , cuando indican que en los derechos reales limitados, con independencia de los efectos reales de los mismos, contienen un entramado o tejido que de modo básico es puramente obligatorio, siendo ello lo normal dentro del desenvolvimiento de los derechos reales. 
la facultad de enajenar la cosa afectada, mediante trámites procesales establecidos, para obtener el valor de la misma y satisfacer el crédito al que acceden. En este grupo se encuentran la hipoteca, la prenda y anticresis $^{51}$.

Descartado que se trate técnicamente de una desmembración del dominio y que, en consecuencia, el propietario no se desprenda de facultad alguna en favor del acreedor hipotecario -como sí podría argumentarse en los derechos reales de goce o disfrute-, debemos analizar el papel que le asigna nuestro sistema a la inscripción constitutiva del derecho real de hipoteca, descartando que opere en tal caso la tradición, como intentaremos explicar.

Para seguir nuestro razonamiento consideramos necesario hacer una prevención. En caso alguno estamos argumentando que la tradición, como modo de adquirir o como constitutivo de la posesión no opere tratándose del derecho real de hipoteca. Lo que argumentamos es que en la constitución de este derecho real no hay, técnicamente hablando, tradición, pero nada obsta que posteriormente, una vez creado el derecho, este pueda transferirse. Así, pensamos nosotros, es nuestra propia legislación la que distingue o separa ambos actos jurídicos, es decir, distingue claramente entre la constitución, por un lado y, la tradición, por otro, en el artículo $52 \mathrm{~N}^{\text {os }} 1$ y 2 del Reglamento del Conservador. Si en la constitución de algunos derechos reales hay tradición, ¿qué sentido tiene haber separado ambos actos en dos numerales distintos? Una opinión similar sostiene el profesor Peñailillo, quien al tratar los derechos reales limitados expone las concepciones del dominio que hemos analizado -el dominio como suma de facultades y el dominio como poder o señorío único-, para descartar la teoría de la suma de facultades del dominio, expone: "El Reglamento del Conservador, que distingue entre la tradición del derecho real (ya constituido) y la constitución (efectuada por el propietario) del mismo (art. $52 N^{\text {as }} 1$ y 2 , respectivamente), supone la idea contraria" ${ }^{2}$. Ello

51 Diez PiCAZo y Gullón: (n 30), pp. 45 y 46. La misma explicación formula SALVAT: (n 48), pp. 26,27 y 29 para descartar el carácter de desmembración de dominio de la hipoteca. Señala que la hipoteca puede entenderse como derecho real si se comprenden los derechos reales en general no como desmembraciones del dominio, sino como una limitación al ejercicio de ella, siendo en la hipoteca el valor económico de la cosa dada en garantía.

52 PeÑailillo: (n 23), p. 306. Además, como explica Hernández Esparanza, Domingo: en AAVV Estudios sobre reformas al Código Civil y Código de Comercio. Cuarta parte. Derecho registral inmobiliario. Editorial Jurídica de Chile. Santiago. 2003, pp. 218-221, la inscripción traslativa y la constitutiva de derechos reales tienen una diferencia técnica bastante marcada. Si bien ambas pueden calificarse de constitutivas, en el sentido técnico del derecho registral, es decir, que importan la creación de un derecho real o el traspaso del mismo, las traslativas no son obligatorias, pues nuestro sistema no fija plazo para la inscripción ni prevé la sanción de nulidad en el caso de su omisión, de manera que la tradición propiamente dicha solo permite establecer en nuestro sistema una presunción de 
es porque, como indica Barcía, nuestro Reglamento del Conservador se inspiró especialmente en la legislación alemana ${ }^{53}$.

Por último, a nuestro juicio, la tradición supone que el derecho ya se ha constituido, que ya se encuentra en el patrimonio del titular, pues precisamente la tradición es la forma de hacer la transferencia del derecho real. Se trata, en efecto, de un modo de adquirir derivativo, es decir, que el derecho es traspasado de un antecesor. Solo en ese caso, si el traspaso se opera por alguien que no es dueño, podrá constituir en poseedor al adquirente (artículos 682 y 683 del Código Civil). Pero en la constitución de la hipoteca, no existe tal traspaso, ni desprendimiento de facultades, como se ha analizado. En cuanto al papel de la tradición, coincide con nosotros Víctor Vial: "Lo primero que cabe advertir es que la tradición no crea un derecho. Solamente opera el traspaso del derecho de dominio que ya existía, de manos del antiguo titular a uno nuevo. Si se estimara que la tradición es una convención por medio de la cual se crea un derecho, debería atribuírsele la naturaleza jurídica de un contrato, definido como la convención generadora de derechos y obligaciones, lo que iría abiertamente en contra de la doctrina de nuestro Código Civil, que distingue entre el contrato-título-por una parte y la tradición, por otra" 54 .

posesión, de modo que como indica Barcia LehmanN, Rodrigo: La influencia del Code Civil y del derecho alemán en el sistema patrimonial chileno: sistema de derechos reales y personales en AA.Vv. Estudios de Derecho Civil, LexisNexis, Santiago. 2005, p. 93, la tradición se desvincula casi totalmente del campo del dominio para radicarse en la posesión. En cambio, las constitutivas de derechos reales -como la hipoteca-, al importar solemnidad del acto, son propiamente constitutivas, pues encierran obligatoriedad para ser practicadas y traen como consecuencia que prueban el dominio que se ha creado. Al respecto, señala HERNÁNDEZ: "...tanto las unas como las otras -refiriéndose a las distintas inscripciones de constitución de derechos reales- son de naturaleza constitutiva, en cuanto indispensables para la generación del respectivo derecho real, garantizando tanto la posesión como el dominio del mismo".

53 BARCIA: (n 52), p. 93, agregando que nuestro sistema registral no se inspiró, a diferencia de varios latinoamericanos en la Ley Hipotecaria española del año 1861, pues esta es posterior al Reglamento del Conservador que hasta nuestros días rige. En el sistema registral español, a diferencia del nuestro, la tradición de los bienes raíces se efectúa por la entrega real o simbólica, tal como acontece con los bienes muebles, pero la inscripción contituye un requisito e oponibilidad a terceros. Sobre el particular, DIEZ PICAZO Y GULlón: (n 30), pp. 269 y siguientes. Sobre los distintos sistemas registrales, puede consultarse a HERNÁNDEZ: (n 52), pp. 108 y sigữientes, quien analiza el sistema francés, alemán, español y el de países anglosajones, entre otros.

54 VIAL Del Río: (n 24), p. 5 . En un sentido similar, ROZAS: (n 26), p. 159. En el derecho comparado, por ejemplo, en España, aun cuando el sistema registral, como hemos visto opera de manera distinta, no se considera que en la constitución de la hipoteca haya una tradición. Así, por ejemplo, LASARTE: (n 38), p. 87, refiriéndose a la inscripción de la hipoteca, la considera constitutiva y explica: "Semejante exigencia -la de la inscripciónviene requerida por el becho de que, no babiendo traslación posesoria al acreedor...". 


\section{CONCLUSIONES}

Las categorías dogmáticas se nos presentan comúnmente como inamovibles. Este trabajo ha intentado poner en la discusión una de esas categorías inamovibles de la enseñanza en nuestro sistema jurídico: el que los contratos, como fuentes de las obligaciones, no producen jamás efectos reales y que acogiendo nuestra legislación el sistema romano, para la adquisición de derechos reales se necesita de dos actos jurídicos; así, se requiere de un título, constituido por el contrato (acto jurídico bilateral creador de derechos y obligaciones), seguido de un modo de adquirir (también un acto jurídico, denominado tradición, que correspondería técnicamente a una convención).

Este sistema explica bastante bien la generalidad de las figuras jurídicas y de hecho, no nos cabe la menor duda que es el que opera en la gran mayoría de los casos. Pero se ha transformado en la única explicación posible para la adquisición de derechos reales, estructurándose un sistema rígido, que no admite excepciones y en el que a veces se hacen grandes esfuerzos de adecuación o se termina por reconocer algunos vacíos, pero sin profundizar en ellos. Por ello, hemos propuesto que no obstante admitir nuestro sistema el de la dualidad título-modo, ello no significa que en dicha recepción están matices o acercamientos al sistema francés del efecto real. De esta manera lo han reconocido varios autores nacionales, que han enunciado casos que nosotros no nos detenemos. Así, se hace mención a la cesión de los créditos no documentarios y a la tradición que opera en los contratos reales, como el mutuo. Nosotros nos hemos detenido en dos hipótesis distintas: en algunas formas de tradición ficta, que aunque reguladas como tradición, sustantivamente implican adjudicarle efecto real al contrato y, especialmente la constitución del derecho real de hipoteca, pues en este no existe desmembración del dominio que permita afirmar la existencia de una tradición. Estos casos ponen de manifiesto que las explicaciones generales en el Derecho no pueden transformarse en esquemas rígidos, pues hay instituciones que escapan de dichos marcos generales. De algún modo, estos problemas vienen porque hemos permanecido arraigados a un concepto demasiado estricto del contrato, que lo restringe al papel de creador del derecho y fuente de obligaciones, aunque la definición del artículo 1438, como se ha analizado en esta investigación, no lo haya consagrado en esos términos.

\section{BIBLIOGRAFÍA}

- Abeliuk Manasevic, René: Las obligaciones, Editorial Jurídica de Chile, Santiago, 2001.

- Alessandri Rodríguez, Arturo: De los contratos, Editorial Jurídica de Chile, 1993. 
- Alessandri Rodríguez, Arturo. Somarriva Undurraga, Manuel. VodANOvic H., Antonio: Tratado de los derechos reales, Editorial Jurídica de Chile, Santiago, 2001.

- Alessandri, Fernando: Memoria de prueba, Universidad de Chile, Santiago, 1919.

- Barcía Lehmann, Rodrigo: La influencia del Code Civil y del derecho alemán en el sistema patrimonial chileno: sistema de derechos reales y personales en AA.Vv. Estudios de Derecho Civil, LexisNexis, Santiago. 2005.

- Corral Talcciani, Hernán. La definición de contrato en el Código Civil Chileno y su recepción doctrinal. Comparación con el sistema francés, en Documentos de Trabajo. Universidad de los Andes. $\mathrm{N}^{\circ} 43$. Posteriormente en AA.Vv. Derecho de los contratos, Facultad de Derecho de la Universidad de los Andes, Cuadernos de extensión jurídica. 2002.

- Cueto RÚA, Julio: Una concepción objetiva del contrato. El caso del Common Law, en AA.Vv., Contratos. Ediciones La Roca, Buenos Aires, 1989.

- D'ors, Álvaro: Derecho Privado Romano, Ediciones Universidad de Navarra S.A., Pamplona, 1997.

- Diez Duarte, Raúl: La Hipoteca en el Código Civil chileno, Pacsed editores, Santiago, 1991.

- Diez Picazo, Luis. Gullón, Antonio: Sistema de Derecho Civil. Volumen III. Derecho de cosas y Derecho inmobiliario Registral, Editorial Reus, Madrid, 2000.

- EnNeccerus, Ludwig. Kipp, Theodor. WOlF, Martín: Tratado de Derecho Civil. Tomo I. Vol. 1. Derecho de cosas, Editorial Bosch, Barcelona, 1971.

- Fabré-Magnan, Muriel: Les obligations, Presses Universitaires de France, Paris, 2004.

- Floris Magadant, Guillermo: El Derecho Privado Romano, Editorial Esfinge, Naucalpán, México, 1991.

- García Garrido, Manuel: Derecho Privado Romano. Casos, acciones, instituciones, Editorial Dykinson, Madrid, 1998.

- Hedeman: Tratado de derecho civil. Tomo II. Derechos reales, Editorial Revista de Derecho Privado, Madrid, 1955.

- Hernández Esparanza, Domingo: en Aa.Vv. Estudios sobre reformas al Código Civil y Código de Comercio. Cuarta parte. Derecho registral inmobiliario. Editorial Jurídica de Chile. Santiago. 2003.

- Lasarte Álvarez, Carlos: Principios de derecho civil. Tomo V. Propiedad y derechos reales. Editorial Trivium. Madrid. 2001.

- LÓPez SANTA MARía, Jorge: Los contratos. Parte general. Tomo I, Editorial Jurídica de Chile, Santiago, 1998.

- Meza Barros, Ramón: Manual de Derecho Civil. De las fuentes de las obligaciones. Tomo II, Editorial Jurídica de Chile, Colección de manuales jurídicos, 1960. 
- Peñailillo Arévalo, Daniel: Los bienes. La propiedad y otros derechos reales, Editorial Jurídica de Chile. Colección de manuales jurídicos, Santiago, 2002.

- Peñallillo Arévalo, Daniel: Obligaciones., Editorial Jurídica de Chile, Santiago, 2003.

- Puig BRUtAu, José: Fundamentos de Derecho Civil, Editorial Bosch, Barcelona, 1983.

- Rodríguez Grez, Pablo: Responsabilidad contractual, Editorial Jurídica de Chile, Santiago, 2004.

- ROZAS VIAL, Fernando: Los bienes, Editorial Jurídica ConoSur Limitada, Santiago, 1998.

- Salvat, Raimundo: Tratado de Derecho civil argentino. Derechos reales, Tipográfica Editora Argentina, Buenos Aires, 1960.

- Somarriva, Manuel. Alessandri, Arturo y Vodanovic, Antonio: Tratado de las Obligaciones. De las obligaciones en general y sus diversas clases, Editorial Jurídica de Chile, 2001.

- Somarriva Undurraga, Manuel. Tratado de las cauciones. Editorial Jurídica ConoSur. $1^{a}$ Edición. Santiago. VIAL DEL Río, Víctor: $L a$ tradición y la prescripción adquisitiva como modo de adquirir el dominio, Ediciones P. Universidad Católica de Chile, Santiago, 2003.

- VON TUHR: Tratado de las obligaciones. Traducción de W. Roces. Tomo Primero, Editorial Reus S.A., Madrid, 1999. 